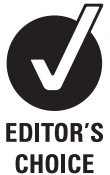

CHOICE
- An additional appendix is published online only. To view this file please visit the journal online (http://thorax.bmj.com/ content/67/5.toc).

${ }^{1}$ Chest Clinic, Doncaster Royal Infirmary, Doncaster, UK

${ }^{2}$ Academic Unit of Respiratory Medicine, Department of Infection and Immunity, Medical School, University of Sheffield, Sheffield, UK

${ }^{3}$ Public Health, NHS Doncaster, Doncaster, UK

${ }^{4}$ Centre for Health and Social Care Research, Sheffield Hallam University, Sheffield, UK

${ }^{5}$ Health Services Research, School of Health and Related Research, University of Sheffield, Sheffield, UK

\section{Correspondence to}

Dr Victoria Athey, Chest Clinic, South Block, Doncaster Royal Infirmary, Armthorpe Road, Doncaster DN2 5LT, UK v.athey@sheffield.ac.uk

Received 30 June 2011 Accepted 15 September 2011 Published Online First 2 November 2011

\title{
Early diagnosis of lung cancer: evaluation of a community-based social marketing intervention
}

\author{
Victoria L Athey ${ }^{1,2}$ Rupert J Suckling, ${ }^{3}$ Angela M Tod, ${ }^{4}$ Stephen J Walters, ${ }^{5}$ \\ Trevor K Rogers ${ }^{1}$
}

\begin{abstract}
Background Poor UK lung cancer survival rates may, in part, be due to late diagnosis.

Objectives To evaluate the effectiveness of a mixedmethod community-based social marketing intervention on lung cancer diagnoses.

Methods A public awareness campaign in conjunction with brief intervention training in general practices was piloted in six localities with a high lung cancer incidence. End points were self-reported awareness of lung cancer symptoms; intention to seek healthcare; chest x-ray referral rates in primary care; secular trends in the incidence of lung cancer and stage at diagnosis, compared before and after the intervention. Results $21 \%(128 / 600)(95 \% \mathrm{Cl} 18 \%$ to $25 \%$ ) of the targeted population recalled something about the campaign. Compared with a responder in the control area, the odds of a responder in the intervention area saying that they would visit their general practitioner and

\section{Key messages}

What is the key question?

- Can a combined public awareness campaign and GP education programme increase chest $x$ ray referral numbers and promote lung cancer diagnosis.

\section{What is the bottom line?}

- This combined approach increased chest x-ray referral numbers in those areas targeted by the campaign.

Why read on?

- This approach offers a means to promote symptom reporting and chest $\mathrm{X}$-ray referral in primary care, with the potential to improve lung cancer outcomes through earlier diagnosis.
\end{abstract} request a chest $x$-ray for a cough was 1.97 times (95\% Cl 1.18 to $3.31, p=0.01)$. Primary care chest $x$-ray referral rates increased by $20 \%$ in the targeted practices in the year following the intervention compared with a $2 \%$ fall in the control practices. The difference was highly significant, with an incidence rate ratio of 1.22 (95\% Cl 1.12 to $1.33, p=0.001)$. There was a $27 \%$ increase in lung cancer diagnoses in the intervention area compared with a fall in the control area. The incidence rate ratio was 1.42 (95\% $\mathrm{Cl} 0.83$ to $2.44 \mathrm{p}=0.199)$.

Conclusion This is encouraging early evidence that an awareness and early recognition initiative may facilitate lung cancer diagnosis.

\section{INTRODUCTION}

Lung cancer is the most common cancer in the world, with 1.6 million new cases diagnosed every year. ${ }^{1}$ In the UK it accounts for 14\% (39400 cases per year) of all cancer diagnoses and $22 \%$ of all cancer deaths ${ }^{2}$ and is more prevalent in areas with high levels of social deprivation. ${ }^{3}$ Prognosis is dependent on disease stage at diagnosis. Early stage disease can be cured by radical treatment: 5-year survival rates for people with stage I tumours treated with radical surgery are between $60 \%$ and $80 \% .{ }^{4-6}$ Unfortunately, at present more than twothirds of UK cases are diagnosed at an advanced stage and survival rates are among the lowest in the developed world. One-year survival is $27 \%$ and 5 -year survival is only $8 \%{ }^{7}$ compared with the USA (13\% for men and $17 \%$ for women), ${ }^{8}$ and other
European countries including Austria, France and Spain (10-15\%, European average 12\%). ${ }^{7} \mathrm{~A}$ comparison of survival rates in England, Norway and Sweden suggests that differences in survival are apparent as early as 3 months from diagnosis, suggesting that a significant contributor to low 5 -year survival rates in England may be very early death. It is felt that this is most likely due to more advanced disease at presentation in England. ${ }^{9}$ Furthermore, the rates of $x$-rays obtained in the UK have been noted to be substantially lower than in Norway and Sweden, supporting the hypothesis that reduced access to chest $\mathrm{x}$-rays may contribute to late presentation. ${ }^{10}$

Over $90 \%$ of patients are symptomatic at the time of diagnosis ${ }^{11}$ with patients experiencing two to three symptoms on average. ${ }^{12}$ Cough is the most common presenting symptom ${ }^{12-16}$ and has been noted to be a good prognostic indicator. ${ }^{12}$ Studies have shown that patients have often been symptomatic for several months before presenting for medical attention, ${ }^{15-18}$ at least in part due to a lack of awareness of the significance of the experienced symptoms. ${ }^{15} 16 \quad 18$ It has also been shown that many patients will visit their general practitioner (GP) on more than one occasion before further investigation or onward referral. ${ }^{16}$ There is a growing lobby to address patient-induced and service-induced delays in lung cancer diagnosis and intervention. Early diagnosis of lung cancer is a stated UK government priority, ${ }^{19-21}$ reflected in the establishment of the National Awareness and 
Early Detection Initiative. ${ }^{22} \mathrm{~A}$ chest $\mathrm{x}$-ray is usually the initial investigation for symptoms suggestive of lung cancer, as recommended by the National Institute for Health and Clinical Excellence (NICE) ${ }^{20}$ However, there is some concern that chest $\mathrm{x}$-rays are not obtained as often as might be clinically indicated. $^{23}$

Doncaster is a large metropolitan borough in England, with a population of 289828 . It has a higher than average annual incidence of lung cancer (61.8/100000 compared with 45.9/ 100000 in England between 2004 and 2006), ${ }^{24}$ probably reflecting cigarette smoking rates in association with high levels of social deprivation. A number of barriers in the lung cancer journey have been highlighted by qualitative research with Doncaster patients. ${ }^{25}$ Reasons for the delay in diagnosing lung cancer from a patient perspective included the nature of symptoms people experienced, a mismatch between expectation and experience of symptoms, lack of awareness of symptoms and their initial response to the symptoms.

Social marketing uses a range of communication strategies and marketing techniques to change health behaviour. ${ }^{26} 27$ Several studies have used social marketing interventions in an attempt to promote cancer symptom awareness and/or early presentation, summarised in a systematic review by Austoker et $a .^{28}$ In six studies of community-level interventions they found limited evidence of effectiveness in promoting cancer awareness, some evidence suggesting that the time from symptom recognition to presentation can be reduced and that disease may be identified at an earlier stage. In only one study was there evidence of a prolonged effect of the campaign. The authors did not identify any studies of social marketing interventions in lung cancer.

This pilot project was designed to overcome barriers to presentation and improve detection of lung cancer symptoms by the use of a social marketing campaign, with a view to wider implementation across Doncaster. The project aimed to increase the number of symptomatic patients presenting at GP surgeries and to increase chest $\mathrm{x}$-ray referrals by $20 \%$.

\section{METHODS}

\section{Setting and participants}

The project was commissioned by the Public Health Department of the local Primary Care Trust (PCT) to address a recognised area of health inequality. Six priority communities served by 11 GP surgeries were identified as those at highest lung cancer risk, with high rates of smoking and high levels of social deprivation. The number of communities selected for the intervention was based on the number of GP practices that could be visited by the team running the brief intervention training. Five control communities, served by nine GP surgeries, were selected for the evaluation. The control communities were geographically removed from the intervention areas but had similar demographics. It was recognised that the control area residents would inevitably be contaminated, to some degree, by the public awareness campaign.

\section{Interventions}

Two complementary interventions were developed, with a 'push-pull' approach being used.

The 'push' included a public awareness campaign, face-to-face events and conversations that focused on raising awareness of the importance of seeking medical advice and requesting a chest $\mathrm{x}$-ray for a cough lasting more than 3 weeks. Prolonged cough was selected as the focus of the campaign because of the

\section{Box 1 Public campaign interventions}

Local free paper and Local press

Local radio

Leaflets

Beer mats

Bus stops (4 with a sound chip that coughed)

Pharmacy bags

Outdoor billboards (see figure 1)

evidence that it may be associated with a better prognosis and for the simplicity of the message. Partnerships were established with creative, media and public relations agencies to design and develop the awareness campaign. Insights for the campaign came from the earlier local qualitative research ${ }^{25}$ and geodemographic profiling conducted by Yorkshire and Humber Public Health Observatory (personal communication). The scoping, development, implementation and evaluation stages were conducted using a social marketing approach ${ }^{26}{ }^{27}$ and are described elsewhere. ${ }^{29}$ The campaign was primarily aimed at men aged over 50 who had ever smoked and/or worked in heavy industry and their family members. In response to the earlier insight gathered, ${ }^{25}$ it did not specifically mention cancer and made no reference to smoking. An integrated mix of media was used (see box 1). The campaign was enhanced by a 'coughing' bus shelter, where a sound chip coughed repeatedly to draw attention to the message. The public campaign was launched in March 2008 and ran for 6 weeks.

Measures used to 'pull' patients through healthcare services included brief intervention training to prepare healthcare professionals for the initiative and reassure them that there was sufficient capacity within the radiology department and secondary care to cope with increased referrals. This training involved sharing insights, training and capacity management in GP surgeries. Professionals were reminded of the NICE chest x-ray referral criteria and a workbook ${ }^{30} 31$ was provided. Community pharmacists were included and encouraged to promote the campaign materials to those buying over-thecounter cough medication. GP practices were visited and training delivered prior to the public campaign launch.

Following on from the campaign, its impact on secondary care services and lung cancer diagnosis rates was examined.

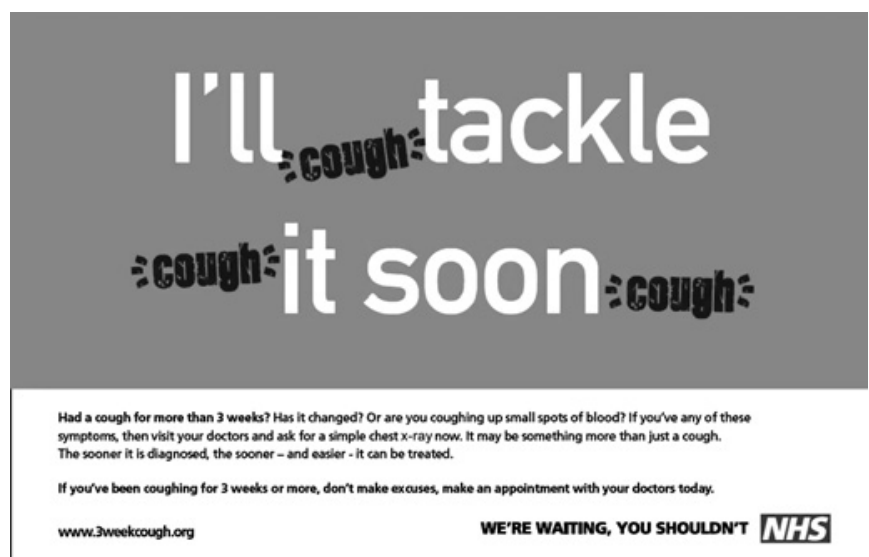

Figure 1 A poster used on billboards and in the local press. 
Following discussion with the local NHS research ethics committee they reassured us that it fell under the remit of service evaluation/audit and did not require NHS ethics approval.

\section{Data collection and analysis}

The public awareness campaign was evaluated using a telephone survey of 801 members of the general public before the campaign, as a baseline, and 800 after. The survey, designed by a market research consultancy in collaboration with the Department of Public Health, measured public awareness of lung cancer symptoms and intention to seek healthcare. Both men and women over 50 were contacted, with a slight bias towards men as the primary focus of the campaign. Participants were spread across the six priority communities and a single control community and were identified using random digit dialling. A list of available telephone numbers, within the target area, was obtained from Oftel, checked to ensure that they were assigned to a residential property and 'active' numbers were placed in a database. The sample was then created by assigning random numbers to the active numbers on a one in three basis. The age of the respondents was established by direct questioning at the beginning of any telephone contact. Self-reported outcomes recorded included awareness of lung cancer symptoms and intention to seek healthcare (see online appendix for the full questionnaire).

The data from the post-campaign interviews were matched to the initial interviews using demographic variables to maximise the accuracy of before and after comparisons. The baseline
Table 1 Characteristics of communities (2004 data)

\begin{tabular}{|c|c|c|c|}
\hline & Intervention area & Control area & $\overline{\text { Doncaster }}$ \\
\hline Number of communities & 6 & 5 & \\
\hline \multicolumn{4}{|l|}{ Population } \\
\hline Mean per community & 2777 & 7816 & \\
\hline Range & $898-6365$ & $5257-11338$ & \\
\hline Total & 16660 & 38991 & 286862 \\
\hline $\begin{array}{l}\text { Classification of household } \\
\text { deprivation (range) }\end{array}$ & $41.3(43.8-38.4)$ & $37.7(36.7-40.1)$ & \\
\hline $\begin{array}{l}\text { Lung cancer incidence } \\
\text { (age standardised per } \\
100000 \text { pop/year) (range) }\end{array}$ & $130(100-160)$ & $79(59-95)$ & 65.1 \\
\hline $\begin{array}{l}\text { Lung cancer mortality } \\
\text { (per } 100000 \text { pop/year) } \\
\text { (range) }\end{array}$ & $69(53-91)$ & $45(37-58)$ & 39.1 \\
\hline
\end{tabular}

survey was conducted from 18 March to 27 March 2008 and the post-campaign survey from 19 May to 6 June 2008.

Chest x-ray data were retrospectively gathered from the Radiology Information System at Doncaster Royal Infirmary. The numbers of chest $\mathrm{x}$-rays requested by the priority practices over the 6 weeks before and after the interventions were recorded. These were compared with the GP x-ray request rates across the whole PCT for the same periods. Data were subsequently collected for the intervention and control practices for 1 year before the campaign and 1 year after the campaign.

All lung cancer cases in Doncaster have been prospectively recorded since 1998. The dataset includes demographics, tumour characteristics, treatment modalities and outcomes. The database was searched to identify the number of diagnoses and

Table 2 Demographic characteristics of telephone survey participants

\begin{tabular}{|c|c|c|c|c|}
\hline & \multicolumn{4}{|l|}{ Time } \\
\hline & \multicolumn{2}{|l|}{ Pre-intervention } & \multicolumn{2}{|l|}{ Post-intervention } \\
\hline & Control area, n (\%) & Intervention area, $\mathbf{n}(\%)$ & Control area, n (\%) & Intervention area, $\mathbf{n}(\%)$ \\
\hline Men & $177(89)$ & $360(60)$ & $124(62)$ & $426(71)$ \\
\hline Women & $22(11)$ & $242(40)$ & $76(38)$ & $174(29)$ \\
\hline Total & $199(100)$ & $602(100)$ & $200(100)$ & $600(100)$ \\
\hline \multicolumn{5}{|l|}{ Age group (years) } \\
\hline $60-69$ & $60(30)$ & $203(34)$ & $56(28)$ & $226(38)$ \\
\hline $70+$ & $88(44)$ & $251(42)$ & $116(58)$ & $290(48)$ \\
\hline Total & $199(100)$ & $602(100)$ & $200(100)$ & $600(100)$ \\
\hline \multicolumn{5}{|c|}{ Are you or have you ever been a smoker? } \\
\hline Yes, currently a smoker & $33(17)$ & $115(19)$ & $31(15.5)$ & $107(18)$ \\
\hline Yes, but not now a smoker & $112(56)$ & $280(47)$ & $113(56.5)$ & $305(51)$ \\
\hline Working part time & $8(4)$ & $48(8)$ & $5(3)$ & $14(2)$ \\
\hline At school/college/university & & & $1(1)$ & \\
\hline Housewife/househusband & $2(1)$ & $7(1)$ & $2(1)$ & $8(1)$ \\
\hline Unemployed & $7(4)$ & $25(4)$ & $2(1)$ & $26(4)$ \\
\hline Retired & $144(72)$ & $420(70)$ & $169(84)$ & $498(83)$ \\
\hline On sick/disability & & & & $9(2)$ \\
\hline Total & $199(100)$ & $602(100)$ & $200(100)$ & $600(100)$ \\
\hline \multicolumn{5}{|l|}{ Socio-economic group } \\
\hline C2 & $82(41)$ & $266(44)$ & $55(28)$ & $258(43)$ \\
\hline D & $105(53)$ & $244(41)$ & $87(43)$ & $283(47)$ \\
\hline $\mathrm{E}$ & $12(6)$ & $92(15)$ & $58(29)$ & $59(10)$ \\
\hline Total & $199(100)$ & $602(100)$ & $200(100)$ & $600(100)$ \\
\hline
\end{tabular}


Table 3 Outcomes from telephone survey before and after the intervention by area

\begin{tabular}{|c|c|c|c|c|c|c|c|c|}
\hline \multirow[b]{3}{*}{ Outcome } & \multicolumn{4}{|l|}{ Time } & \multicolumn{4}{|c|}{ Area ${ }^{*}$ time interaction $\neq$} \\
\hline & \multicolumn{2}{|l|}{ Pre-intervention } & \multicolumn{2}{|l|}{ Post-intervention } & \multicolumn{2}{|l|}{ Unadjusted } & \multicolumn{2}{|l|}{ Adjusted $\dagger$} \\
\hline & Control area, $\mathrm{n}(\%)$ & Intervention area, $\mathbf{n}(\%)$ & Control area, $\mathrm{n}(\%)$ & Intervention area, $\mathbf{n}(\%)$ & $\overline{\text { OR }(95 \% \mathrm{Cl})}$ & p Value & $\overline{\mathrm{OR}}(95 \% \mathrm{CI})$ & p Value \\
\hline Yes & $85(43)$ & $244(41)$ & $79(40)$ & $269(45)$ & $1.36(0.86$ to 2.16$)$ & 0.188 & 1.41 (0.88 to 2.28$)$ & 0.157 \\
\hline Total & $199(100)$ & $602(100)$ & $200(100)$ & $600(100)$ & & & & \\
\hline \multicolumn{9}{|c|}{ Likelihood of visiting GP with a bad cough and asking for $x$-ray } \\
\hline \multicolumn{9}{|c|}{ Would leave cough no more than 3 weeks before visiting GP } \\
\hline Yes & $31(16)$ & $140(23)$ & $41(21)$ & $117(20)$ & 1.75 (0.98 to 3.14$)$ & 0.061 & 1.47 (0.80 to 2.70$)$ & 0.217 \\
\hline Total & $199(100.0)$ & $602(100.0)$ & $200(100.0)$ & $600(100.0)$ & & & & \\
\hline
\end{tabular}

†Adjusted for time, area, sex, age group, socio-economic group and smoking status.

$\ddagger$ The interaction term represents the change over time in the outcome (ie, post minus pre) for the intervention area minus the same effect for the control area

patient characteristics in the intervention and control practices for 1 year before and 1 year after the intervention.

For the post-telephone survey, an important outcome was the self-reported likelihood of visiting the GP with a bad cough and requesting an x-ray. If three times as many people in the intervention area compared with the control area were surveyed, with 800 responders to the survey (600 intervention, 200 control) the power to detect a $10 \%$ absolute difference (from an estimated baseline of $70 \%$-based on an estimate from qualitative interviews with patients and the general public conducted during a feasibility study of this intervention in 2007 in a single Doncaster general practice (unpublished) - to $80 \%$, equivalent to an OR of 1.71 ) would be approximately $80 \%$ at the $5 \%$ two-side level. The authors regarded a difference of $10 \%$ or more as likely to be of clinical or practical importance.

To test the efficacy of the campaign on binary outcomes from the baseline and follow-up telephone surveys, such as selfreported awareness of lung cancer symptoms and intention to seek healthcare, a logistic regression model was used. This included time, area, and time by area interaction terms. The OR for this interaction term and its associated 95\% CI are reported. The authors also adjusted for other covariates such as sex, age group, socio-economic group and smoking status.
Changes in discrete outcomes such as the number of chest $\mathrm{x}$-ray referrals in primary care and the incidence of lung cancer were compared among the areas with a Poisson regression model. The number of lung cancer diagnoses in each practice in each area before and after the intervention was used as the outcome variable, and time (before or after the intervention), area (control or intervention) and an area by time interaction term were covariates. The different populations at risk in the two areas were accounted for in the model by including the practice list size (number of adults) as an exposure or offset variable. The incidence rate ratio (IRR) for the interaction term and its associated 95\% CI are reported.

\section{RESULTS}

Table 1 shows the deprivation and lung cancer statistics for the intervention and control areas. The control area is slightly less deprived compared with the intervention area and has lower lung cancer incidence and mortality rates.

Overall $76 \%(1601 / 2107)$ of people responded to the telephone survey, 801 before the campaign and 800 after the campaign. Table 2 shows the demographic characteristics of the four groups of participants. The uneven distribution between the groups was adjusted for in the analysis. Survey responses indicated that

Table 4 Numbers of new lung cancer diagnoses and x-rays (and practice populations) and incidence rates in the 12 months before (March 2007-February 2008) and 12 months after (March 2008-February 2009) the intervention

\begin{tabular}{|c|c|c|c|c|c|c|c|}
\hline & \multirow[b]{2}{*}{ Outcome } & \multicolumn{2}{|l|}{ Area } & \multirow[b]{2}{*}{$\begin{array}{l}\text { IRR Int } \\
\text { versus Cont }\end{array}$} & & & \multirow[b]{2}{*}{ p Value } \\
\hline & & $\begin{array}{l}\text { Control } \\
\text { (n=9 practices) }\end{array}$ & $\begin{array}{l}\text { Intervention } \\
\text { ( } n=11 \text { practices) }\end{array}$ & & \multicolumn{2}{|c|}{ 95\% CI for IRR } & \\
\hline \multicolumn{8}{|l|}{ Time } \\
\hline \multirow[t]{3}{*}{ Before } & Number of lung cancer diagnoses & 47 & 59 & & & & \\
\hline & Population at risk & 43444 & 67119 & & & & \\
\hline & Rate/100 000 population/year & 108 & 88 & 0.81 & 0.55 & 1.19 & 0.288 \\
\hline \multirow[t]{3}{*}{ After } & Number of lung cancer diagnoses & 42 & 75 & & & & \\
\hline & Population at risk & 43444 & 67119 & & & & \\
\hline & Rate/100 000 population/year & 97 & 112 & 1.16 & 0.79 & 1.69 & 0.452 \\
\hline Interaction* & & & & 1.42 & 0.83 & 2.44 & 0.199 \\
\hline \multicolumn{8}{|l|}{ Time } \\
\hline \multirow[t]{3}{*}{ Before } & Number of $\mathrm{x}$-rays & 1605 & 2875 & & & & \\
\hline & Population at risk & 43444 & 67119 & & & & \\
\hline & Rate/100 000 population/year & 3690 & 4280 & 1.16 & 1.09 & 1.23 & 0.001 \\
\hline \multirow[t]{3}{*}{ After } & Number of $x$-rays & 1573 & 3442 & & & & \\
\hline & Population at risk & 43444 & 67119 & & & & \\
\hline & Rate/100 000 population/year & 3620 & 5130 & 1.42 & 1.33 & 1.50 & 0.001 \\
\hline Interaction* & & & & 1.22 & 1.12 & 1.33 & 0.001 \\
\hline
\end{tabular}

*The interaction term represents the change over time in the outcome (ie, after minus before) for the intervention area minus the same effect for the control area.

Cont, control; Int, intervention; IRR, incidence rate ratio. 
a maximum of $20 \%$ of the population questioned smoke. This is in stark contrast to the actual smoking prevalence in these areas of $36-42 \%$ (Rupert Suckling, personal communication).

Post-campaign survey results indicated that 21\% (128/600; $95 \%$ CI $18 \%$ to $25 \%$ ) of people in the intervention community recalled something about the campaign.

Table 3 shows that there was a small increase in the intervention area in people who indicated that they would visit their GP for a cough lasting more than 3 weeks. People who would also request a chest $\mathrm{x}$-ray increased in the intervention area, while falling in the control area. When compared with a responder in the control group, the odds of a responder in the intervention group saying that they would visit their GP and request a chest $\mathrm{x}$-ray for a cough lasting more than 3 weeks was 1.97 times (95\% CI 1.18 to $3.31 \mathrm{p}=0.01)$, after adjustment for covariates

\section{Chest $x$-ray rates}

Comparing the 6 weeks before and during the campaign, the number of chest $\mathrm{x}$-ray referrals across Doncaster increased substantially, by 289 (22\%). In non-targeted practices, 169 more $\mathrm{x}$-rays were obtained (a 19\% increase) and in targeted practices 120 more x-rays were obtained (a 27\% increase). Interestingly, no increase was observed in two of the 11 targeted practices.

While the study was designed to evaluate the short-term effects on chest x-ray referral rates, the durability of the changes in referral rates following the campaign were also examined. Over the 1 year following the intervention, there continued to be an increase in chest $\mathrm{x}$-rays being requested in the intervention area, with an extra 567 chest x-rays (20\% increase) being obtained. In contrast, 32 fewer x-rays (a $2 \%$ fall) were obtained in the control area (see table 4). This represented a statistically significant increase in the numbers of chest $x$-rays over time between the intervention and control areas, with an IRR of 1.22 (95\% CI 1.12 to $1.33, p=0.001)$.

There was a strong relationship between campaign recall, shifts in attitude and the number of chest x-rays ordered (data extrapolated from the 11 targeted GP practices serving these communities). The correlation between the number of chest $\mathrm{x}$-rays performed and intent to see the GP and request a chest $\mathrm{x}$-ray was $0.9(\mathrm{p}<0.01)$ (see figure 2$)$.

\section{Lung cancer diagnoses}

Compared with the year before the intervention, the number of lung cancer diagnoses increased by $27 \%$ in the intervention area

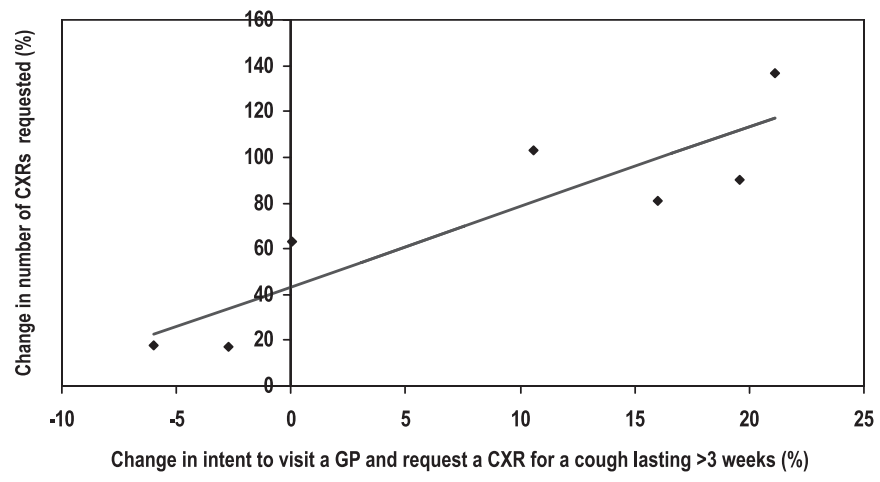

Chest $\mathbf{x}$-rays undertaken (\% change) versus intention to vist GP and ask for $\mathbf{x}$-ray (\% change) (correlation $=0.9$ )

Figure 2 Relationship between change in intent and change in number of chest $\mathrm{x}$-rays (CXRs) requested.

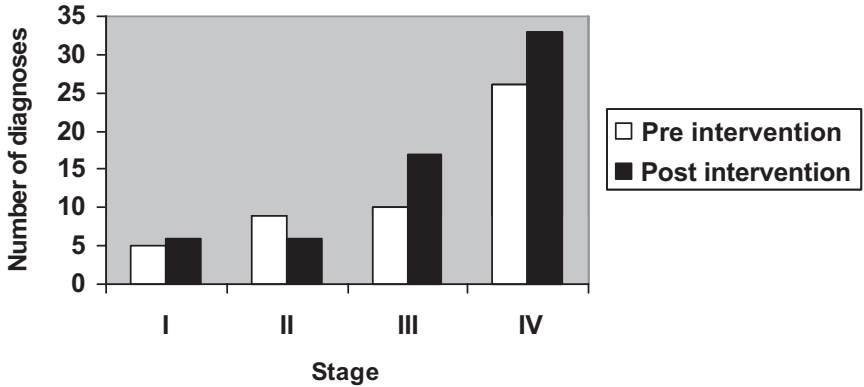

Figure 3 Stage of lung cancer at diagnosis 12 months before (March 2007 to February 2008) and 12 months after (March 2008 to February 2009) the intervention.

practices and fell by $10 \%$ in the control area (see table 4 ). The comparison of the change in diagnosis rates over time between the intervention and control areas showed a positive trend but it did not reach statistical significance, with an IRR of 1.42 (95\% CI 0.83 to $2.43, \mathrm{p}=0.199$ ).

\section{Stage at diagnosis}

No significant stage shift was found at either 3 months, 6 months or 1 year, with increases in diagnoses made at all disease stages, including the most advanced. However the small numbers in the subgroups preclude meaningful statistical analysis (see figure 3).

\section{DISCUSSION}

The campaign had a significant, positive effect on the target audience's stated response towards having a cough lasting more than 3 weeks, leading to an increase in the likelihood of presentation to a GP and requesting a chest x-ray. This stated intention to act was strongly and positively correlated with the actual number of chest x-rays being carried out. This supports the efficacy of the 'push-pull' approach, combining public and professional interventions to increase service access and earlier diagnosis in this socially deprived community with a high incidence of lung cancer.

There is some promising evidence that this increase in people's readiness to report symptoms and the increased number of chest $\mathrm{x}$-ray referrals may have translated into the diagnosis of lung cancer being made earlier. Interestingly this seems to have occurred across the range of disease stages, with apparent increases in the number of cases of advanced disease (stage IV) and early stage disease. While a rise in early stage diagnoses would increase the number of cases eligible for curative interventions, and thereby improve survival, earlier diagnosis of more advanced disease would be expected to increase the number of patients still fit for palliative treatments such as chemotherapy, with potential for improvement in life expectancy and quality of life. This would also lead to a reduction in the number of patients presenting through the emergency admission route.

This study is a pragmatic evaluation that lacks the rigour of a prospective, randomized controlled trial. Evaluating complex interventions of this nature in the real world of community care is challenging. However, these initial positive findings support the need for future experimental evaluations of similar interventions in a larger population. These should examine treatment rates and mortality in order to assess whether there has been any meaningful impact on disease outcome and to review service provision needs and the economic viability of the intervention. The findings of this study did not explain the variation in 
responses. For example, why did people in some of the targeted GP practices respond more positively to the intervention and recall the campaign more readily, and why did x-ray referral rates remain unchanged in two of the practices? Developing an understanding to explain these variations would maximise the impact of future interventions of this nature.

In conclusion, detection of lung cancer may be responsive to a social marketing intervention through raising public awareness, encouraging early reporting of lung cancer symptoms and addressing barriers to chest x-ray referral.

Funding This work was funded by NHS Doncaster (Inequalities fund) and Yorkshire and the Humber Strategic Health Authority (Social marketing collaborative)

Competing interests All authors have completed the Unified Competing Interest form at http://www.icmje.org/coi_disclosure.pdf (available on request from the corresponding author) and declare that (1) VLA, RS, AMT, SJW and TKR received no support for the submitted work; (2) SJW receives occasional consultancy fees for statistical advice in medical negligence claims, payment for training courses on the design and analysis of quality of life measures to statisticians in the pharmaceutical industry and Takeda Plc and book royalties from publishers including John Wiley and Sons Ltd, Blackwell Publishing and Hayward Medical Communications. The department for which SJW works (ScHARR, University of Sheffield) has contracts and/or research grants with the NIHR, HTA and NICE and he is co-applicant on several NIHR portfolio studies. VLA, RS, AMT and TKR have had no relationships with companies that might have an interest in the submitted work in the previous 3 years; (3) their spouses, partners, or children have no financial relationships that may be relevant to the submitted work; and (4) RS provides public health representation on the National Awareness and Early Diagnosis Initiative steering group. SJW is an independent member of the NICE Public Health Interventions Advisory Committee (PHIAC). VLA, TKR and AMT have no non-financial interests that may be relevant to the submitted work."

Ethics approval The evaluation was discussed with the local research ethics committee who felt that it fell under the remit of service evaluation/audit and as a result did not require ethics approval.

Contributors TKR, RS and AMT formed the research development and steering committee. VLA undertook all the data extraction with data analysis performed by SJW. The manuscript was predominantly drafted by VLA and TKR with all authors involved in its revision. The final draft was approved by all authors.

Provenance and peer review Not commissioned; externally peer reviewed.

Data sharing statement Practice level data, used for the statistical analysis, is available from the corresponding author (v.athey@sheffield.ac.uk) on request. Consent was not obtained but the presented data are anonymised and risk of identification is low.

\section{REFERENCES}

1. Ferlay J, Shin HR, Bray F, et al. GLOBOCAN 2008, Cancer Incidence and Mortality Worldwide. http://globocan.iarc.fr (accessed May 2010).

2. Cancer Research UK. Lung Cancer-UK Incidence Statistics. http://info. cancerresearchuk.org/cancerstats/types/lung/incidence/index.htm laccessed Jun 2010)

3. Quinn M, Babb P, Brock A, et al. Cancer Trends in England \& Wales 1950-1999. London: The Stationary Office, 2001.

4. Cancer Research UK. Lung Cancer-Survival Statistics. http://info. cancerresearchuk.org/cancerstats/types/lung/survival/index.htm laccessed Jun 2010)

5. Nesbitt JC, Putnam JB Jr, Walsh GL, et al. Survival in early-stage non-small cell lung cancer. Ann Thorac Surg 1995;60:466-72.
6. Potton E, Janes SM, Spiro SG. The surgical treatment of lung cancer. In: Spiro SG, Huber RM, Janes SM, eds. Thoracic Malignancies. Sheffield: European Respiratory Society Journals Ltd, 2009:187-206.

7. Sant M, Allemani C, Santaquilani M, et al. EUROCARE-4. Survival of cancer patients diagnosed in 1995-1999. Results and commentary. Eur J Cancer 2009;45:931-91.

8. National Cancer Institute. SEER Stat Fact Sheets: Lung and Bronchus. http://seer. cancer.gov/statfacts/html/lungb.html (accessed Jun 2010).

9. Holmberg L, Sandin F, Bray F, et al. National comparisons of lung cancer survival in England, Norway and Sweden 2001-2004: differences occur early in follow-up. Thorax 2010;65:436-41.

10. Rogers TK. Primary care radiography in the early diagnosis of lung cancer. Cancer Imaging 2010;10:73-6.

11. Department of Health. Referral Guidelines for Suspected Cancer. London: The Stationary Office, 2000.

12. Buccheri G, Ferrigno D. Lung cancer: clinical presentation and specialist referral time. Eur Respir J 2004;24:898-904.

13. Hamilton W, Peters TJ, Round $A$, et al. What are the clinical features of lung cancer before the diagnosis is made? A population based case-control study. Thorax 2005; 60:1059-65.

14. Lovgren M, Levealahti $\mathrm{H}$, Tishelman $\mathrm{C}$, et al. Time spans from first symptom to treatment in patients with lung cancer-the influence of symptoms and demographic characteristics. Acta Oncol 2008;47:397-405.

15. Corner J, Hopkinson J, Fitzsimmons D, et al. Is late diagnosis of lung cancer inevitable? Interview study of patients' recollections of symptoms before diagnosis. Thorax 2005; 60:314-19.

16. Bowen EF, Rayner CF. Patient and GP led delays in the recognition of symptoms suggestive of lung cancer. Lung Cancer 2002;37:227-8.

17. Koyi H, Hillerdal G, Branden E. Patient's and doctors' delays in the diagnosis of chest tumors. Lung Cancer 2002;35:53-7.

18. Smith SM, Campbell NC, MacLeod U, et al. Factors contributing to the time taken to consult with symptoms of lung cancer: a cross-sectional study. Thorax 2009;64:523-31

19. Department of Health. Cancer Reform Strategy. London: Department of Health, 2007.

20. National Institute for Clinical Excellence. Lung Cancer: The Diagnosis and Treatment of Lung Cancer. London: National Institute for Health and Clinical Excellence, 2005.

21. National Cancer Research Institute. Lung Cancer Research in the UK: Report of the NCRI Strategic Planning Group on Lung Cancer. London, 2006.

22. Cancer Research UK. The National Awareness and Early Diagnosis Initiative (NAEDI). http://info.cancerresearchuk.org/spotcancerearly/naedi/index.htm (accessed Jun 2010).

23. Stapley S, Sharp D, Hamilton W. Negative chest $x$-rays in primary care patients with lung cancer. Br J Gen Pract 2006;56:570-3.

24. Clinical and Health Outcomes Knowledge Base. http://www.nchod.nhs.uk laccessed May 2010)

25. Tod AM, Craven J, Allmark P. Diagnostic delay in lung cancer: a qualitative study. J Adv Nurs 2008:61:336-43.

26. Evans WD. How social marketing works in health care. BMJ 2006;332:1207-10.

27. Hastings G, McDermott L. Putting social marketing into practice. $B M J$ 2006;332:1210-12

28. Austoker J, Bankhead C, Forbes LJ, et al. Interventions to promote cancer awareness and early presentation: systematic review. Br J Cancer 2009:101 (Suppl 2):S31-9.

29. Suckling R. Early Lung Cancer Intervention in Doncaster, Doncaster 3 Week Cough How to Guide. Cancer Research UK. 2010. http://info.cancerresearchuk.org/ prod_consump/groups/cr_common//@nre/@hea/documents/generalcontent/ cr 043172.pdf (accessed Oct 2010).

30. de Normanville C, Tod AM, Jewell S, et al. Information for General Practitioners. Sheffield: Sheffield Hallam University, 2008. http://info.cancerresearchuk.org/ prod consump/groups/cr common/@nre/@hea/documents/generalcontent/ cr_0̄̈3915.pdf (accessed Dec 2010).

31. de Normanville C, Tod AM, Jewell S, et al. A Guide to Delivering Brief Interventions Sheffield: Sheffield Hallam University, 2008. http://info.cancerresearchuk.org/ prod_consump/groups/cr_common/@nre/@hea/documents/generalcontent/ cr 043916.pdf (accessed Dec 2010). 